\title{
CITIES: Ibero-American Research Network for Sustainable, Efficient, and Integrated Smart Cities
}

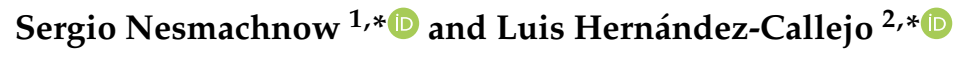 \\ 1 Universidad de la República, Montevideo 11300, Uruguay \\ 2 Departamento Ingeniería Agrícola y Forestal, Universidad de Valladolid, Campus Universitario Duques de \\ Soria, 42004 Soria, Spain \\ * Correspondence: sergion@fing.edu.uy (S.N.); luis.hernandez.callejo@uva.es (L.H.-C.)
}

Received: 23 July 2020; Accepted: 29 July 2020; Published: 31 July 2020

check for updates

\begin{abstract}
This article describes CITIES, the Ibero-American research network for integrated, sustainable, and efficient smart cities. General/specific goals of the network are commented, and participant members are introduced. The main activities developed within the network are described, including research, education, outreach, and dissemination. Finally, some key aspects of the current and future work are presented.
\end{abstract}

Keywords: smart cities; research network; energy efficiency; sustainability; mobility; IoT

\section{Introduction}

The paradigm of smart cities proposes taking advantage of information and communication technologies to improve the quality and efficiency of urban life [1]. The concept of smart city includes several forms of intelligent processes oriented to innovation and adaptation in order to provide better response to challenges of citizens. Furthermore, smart cities rely on the increasingly embedding of smart devices into traditional physical systems, using different sensor devices, such as mobile phones or Internet of Things (IoT) enabled domestic appliances. These devices generate large volumes of data that provide an unprecedented opportunity for extracting useful insights to improve decision-making processes to increase efficiency and improve the quality of life [2]. Several relevant application areas benefit from this new paradigm, including energy and sustainability, education, health, transportation, environment, business, and others.

In this context, this article describes CITIES, the Ibero-American research network for integrated, sustainable, and efficient smart cities, an effort developed in Iberoamerica to promote developing a methodology for strategic planning that helps bring the cities of the region to sustainability through cooperation and knowledge transfer between participating research groups and institutions. This'article presents a description of the main goals and activities of the CITIES network and the milestones achieved during the first two years of the initiative.

The article is organized as follows. Section 2 describes the CITIES network, its main goals and participants. Section 3 summarizes the main activities of the network. Finally, Section 4 elaborates on the impact of the developed activities and forthcoming events.

\section{CITIES Network}

This section describes the goals and participants of the CITIES network.

\subsection{General and Specific Goals}

The general objective of the CITIES network is to develop a strategic planning methodology that helps bring cities in the Ibero-American region towards sustainability through cooperation and 
knowledge transfer between the participating research groups and taking into account the own problems of the cities of the countries that are part of the proposal.

In addition to seek increasing efficiency and sustainability, CITIES recognizes that modern smart cities must be eminently integral. The concept of integrability is crucial, since cities become a multidisciplinary and totally heterogeneous scenario, both in terms of areas of interest and in the partial or global objectives of these areas. Therefore, the CITIES network intends that integrability is the cohesion element of the different fundamental characteristics of smart cities of the future. These characteristics are summarized in three main groups:

- Climate change and environment: Energy (energy efficiency and renewable energy); vulnerability to natural disasters, water, solid waste management, etc.

- Integral urban development: Territorial planning, mobility, security, connectivity, etc.

- Taxation and governance: Governance, cultural heritage, etc.

The specific objectives of the CITIES network include:

- Strengthen the technical and professional training of research centers and participating institutions and, therefore, contribute for the improvement of the quality of life and the environment of Ibero-American citizens.

- Foster new investment opportunities in targeted sectors that can lead to economic diversification and commercial opening of companies, through the identification of barriers and competitive advantages.

- Promote the environmental and economic benefits produced by the incorporation of CITIES among members of the public administration, group of architects, construction companies, financing institutions, companies, research centers, society in general, etc., by carrying out specific directed activities to these groups in a clear commitment to the sustainable development of cities.

- Search for strengths and weaknesses among the participating entities to consolidate a continuous and active exchange of scientific knowledge that allows the development of an action procedure in the cities of Ibero-America, as well as the formulation of future Research \& Development projects that lead to consolidate a future line of work around CITIES.

- Promote meetings of researchers that integrate the participant groups at conferences and seminars, in order to identify potential projects for implementation in the following areas: Intelligent infrastructure, solutions for monitoring and preserving cultural and environmental heritage, applications oriented to efficient and sustainable mobility, promotion of renewable generation sources and energy efficiency in new smart cities, development of solutions for smart cities, and management based on IoT.

- Disseminate the results acquired during the project in usual venues (conferences, seminars, workshops, journal publications, etc.).

- Carrying out specific courses in the different areas of the project: Climate change and the environment, Energy efficiency and sustainability, Comprehensive urban development, Taxation and governance.

- Promote networking to address common problems to Ibero-American countries within the scope of the project. In the same way, the network will serve to identify new participating partners in the research and development, commercial, productive and institutional sectors, including the participation of end users (public administrations and companies).

\subsection{Participant Institutions and Research Groups}

A total number of 56 institutions from 15 countries participate in the network, from academic, public, and private sectors. Participating institutions include:

- Argentina (three institutions) 
o Universidad Nacional de La Plata

o Universidad Gastón Dachary

o Universidad Nacional del Litoral

- Brasil (three institutions)

o Universidade Federal da Paraíba

o Centro Federal de Educação Tecnológica Celso Suckow Da Fonseca

o ATIVA CITI

- Chile (two institutions)

o Universidad de Concepción

o Empresa Eléctrica ENEL Distribución Chile

- Colombia (eight institutions)

o Universidad Javeriana de Cali

o Universidad de Santiago de Cali

o Universidad Libre

o Universidad del Valle

o Universidad Nacional de Colombia

o Universidad de Antioquía

o CINTEL

o CIDET

- Costa Rica (one institution)

o Instituto Tecnológico de Costa Rica

- Cuba (one institution)

o Universidad Central "Marta Abreu” de Las Villas

- Ecuador (two institutions)

o Universidad de Cuenca

o Gobierno Municipal de Cuenca

- Spain (twenty-six institutions:

o Universidad de Valladolid

o Universidad Politécnica de Cataluña

o Universidad Carlos III de Madrid

o Universidad Pointificia Comillas

o Universidad de Salamanca

o Universidad de San Jorge

o Universidad de Zarragoza

o Universidad de las Islas Balearees

o Centro Universitario de la Defensa en la Escuela Naval Militar

o Diputación de Ávila

o AST Ingeniería

o Universidad del País Vasco

o Universidad Complutense de Madrid

o $\quad$ Centro Nacional de Energías Renovables 
o Centro de Desarrollo de Energías Renovables

o Fundación CARTIF

o CODESIAN

o Ente Público Regional de Catilla y León

o FORA Forest Technologies

o INGARTEC

o TECNALIA

o TREELOGIC

o VODAFONE Spain

O ZIGOR

O AYESA

O CIEMAT

- México (three institutions)

o Instituto Politécnico Nacional

o Universidad Autónoma de Baja California

o Universidad Nacional Autónoma de México

- Nicaragua (one institution)

o Universidad Nacional de Ingeniería

- Perú (two institutions)

o Universidad Nacional De Ingenieria

o Universidad del Bio-Bio

- Portugal (one institution)

o Instituto Politécnico de Bragança

- República Dominicana (one institution)

o Instituto Tecnológico de Santo Domingo

- Uruguay (one institution)

o Universidad de la República

- Venezuela (one institution)

o Universidad de Zulia

Figure 1 presents the member institutions of the CITIES research network. Research groups in the project include more than 350 researchers and technicians from academic, public, and private sectors.

A committee of experts including 30 researchers from eleven countries, including expert from institutions outside the network, was appointed to help leading research and education activities within the network. 


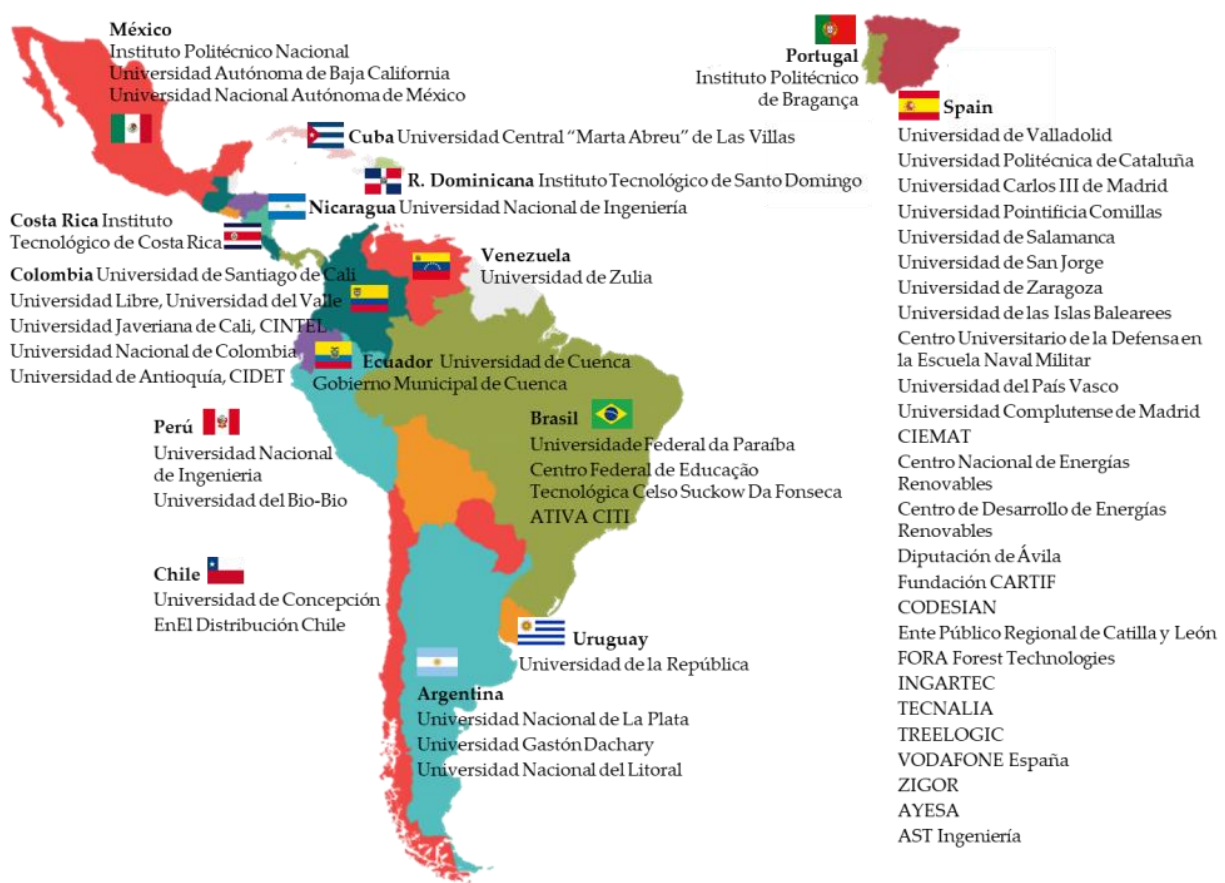

Figure 1. Member institutions of the CITIES research network.

\section{Developed Activities}

This section describes the main activities developed within the CITIES network.

\subsection{Ibero-American Congress of Smart Cities}

The Ibero-American Congress of Smart Cities (ICSC-CITIES) is the annual conference organized by the CITIES network, which gathers researchers, technicians, administration personnel and general audience to discuss project and initiatives related to energy efficiency, sustainability, mobility, governance, and other important subjects related to smart cities.

ICSC-CITIES is conceived as a discussion forum to disseminate both developed an ongoing research activities related to smart cities in the Ibero-American region. The main goal of the event is to create synergies among different research groups to foster the development of smart cities, and contribute to knowledge generation and integration in different scenarios, their possible development and the strategies to address them. The conference receives proposals of scientific articles based on the subject areas defined by the Committee of Experts: Energy Efficiency and Sustainability; Infrastructures, Energy and the Environment; Mobility and IoT; and Governance and Citizenship. The Technical Program Committee gathers more than 100 researchers from all over the world. Two editions of ICSC-CITIES have been organized (in 2018 and 2019), and a third edition will take place in 2020.

ICSC-CITIES 2018 was held in the Auditorium of Duques de Soria University Campus (Soria, Spain) in 6-9 September 2018. A total number of 101 articles were submitted to the conference, and a selection of the best 15 articles were published in Smart Cities, Communications in Computer and Information Science, volume 978, Springer [3]. Extended versions of the best articles were selected for consideration to be published in Revista Facultad de Ingeniería, Universidad de Antioquía, Colombia, indexed in Scopus, Emerging Sources Citation Index (Thomson Reuters-Web of Science), EBSCOhost, SCImago Journal Rank, LATINDEX, SciFinder.

ICSC-CITIES 2019 took place on Soria, on 7-9 October 2019. A total number of 100 articles were submitted to the conference, and a selection of the best 21 articles were published in Smart Cities, Communications in Computer and Information Science, volume 1152, Springer [4]. Extended versions of the best articles were selected for consideration to be published in Revista Facultad de Ingeniería, 
Universidad de Antioquía, Colombia, and in the Special Issue "Mobility and IoT for the Smart Cities" on Smart Cities, MDPI [5].

ICSC-CITIES 2020 is scheduled to be held in Costa Rica, in 9-11 November 2020 (online venue, due to the COVID-19 pandemic). A selection of the best articles submitted to the conference will be published in Smart Cities, Communications in Computer and Information Science, Springer. Extended versions of the best articles will be selected for consideration to be published in Revista Facultad de Ingeniería, Universidad de Antioquía, Colombia and in the Special Issue "CITIES: Energetic Efficiency, Sustainability; Infrastructures, Energy and the Environment; Mobility and IoT; Governance and Citizenship", Applied Sciences, MDPI [6].

The ICSC-CITIES conference is open for researchers, students, academics, administration, and general public. No fees are charged for assistance, article presentation, or participation in tutorials. All accepted articles are publicly available in the proceedings [7,8]. All presentations, events, and discussion panels are recorded and publicly available at the conference website. The conference has been developed with the sponsorship of the Ibero-American Program of Science and Technology for Development (CYTED), Diputación de Soria (Spain), Ayuntamiento de Soria (Spain), Excelentísimo Ayuntamiento de Almazán (Spain), Universidad de Valladolid (Spain), Universidad de la República (Uruguay), Instituto Politécnico de Bragança (Portugal), Universidad Santiago de Cali (Colombia), Universidad Libre (Colombia), Springer Science+Business Media, and Grant Thornton.

\subsection{Development of Capacitation Programs and Courses}

A specific capacitation program is developed within the CITIES network, including presential and online training courses. In addition, workshops and seminars on several subjects of smart cities have been organized. These activities are conducted by specialists of the network and other relevant invited actors.

Several activities were developed in this concern, both in presential and on-line modalities, including:

- Presential seminar "Electric microgrids" at Universidad Santiago de Cali (Colombia), 2018.

- Presential seminar "Photovoltaic systems and their degradation" at Universidad Santiago de Cali (Colombia), 2018.

- Presential seminar at Instituto Politécnico Nacional (México), 2018.

- Presential seminar at Centro Federal de Educação Tecnológica Celso Suckow da Fonseca (Brazil), 2018.

- Presential seminar at Universidad de Cuenca (Ecuador), 2018.

- Tutorial course “Electric microgrids" at Universidad de la República, Uruguay, February 2019. Total participation: 200 assistants from academic, research, productive, university, and administration sectors.

- Presential course, Transient System Simulation Tool, Universidad de Valladolid (Spain), 2018 Armando Aguilar (UABC, México).

- Online course "Infrastructures, Energy and Environment", November 2019, 594 participants from academic, research, productive, and administration sectors.

- Presential seminar "Electric microgrids", Cali (Colombia), July/August 2019, 50 participants from academic, research, productive, university, and administration sectors.

- Presential course "Introduction to photovoltaic systems", Ciudad de México (México), June/July2019, 40 participants from academic, research, productive, and university sectors.

- Presential course, Transient System Simulation Tool, Universidad de Valladolid (Spain), November 2019, 10 participants from academic/university sectors.

- Presential seminary "Photovoltaic systems and its degradation", June/July2019, Cali (Colombia), 50 participants from academic, research, productive, private, and university sectors. 
- Presential course "Mainteinance of photovoltaic systems", Ciudad de México (México), June/July2019, 40 participants from academic, research, productive, private, and university sectors.

- Participation in thematic seminar "Electric mobility", Madrid (Spain), June 2019, 20 participants from public and private sectors.

- Participation in seminar "Sustainable mobility", Madrid (Spain), December 2019, 20 participants from public and private sectors.

The courses and seminars have provided specific formation and training to more than 600 students and practitioners. A large proportion of the participants were post-gratuate student (M.Sc. or Ph.D. studies).

\subsection{Research and Development}

Research groups participating in CITIES network have developed valuable investigations in the research lines included in the initiative. More than 100 articles have been published in journals and conferences, and more than 25 corresponding to joint works between research groups participating in the network.

Some of the most relevant researches and published articles include the energy efficiency studies via computational intelligence for electricity demand forecasting in industrial and residential sectors [9]; IoT developments, such as the proposal of smart bus stops for increasing social inclusiveness and quality of life of elders [10]; electric mobility, such as a power supply solution for electric trains [11]; waste management in modern smart cities [12]; pollution and air quality, such as assessing the effectiveness of low emissions zones [13]; and sustainable mobility in public transportation [14].

\subsection{Dissemination and Outreach}

Several dissemination and outreach activities have been developed within the CITIES network. The most relevant participations in events include:

- Participation in ACELERATOR 2018 Business Architecture, Universidad Santiago de Cali (Colombia), November 2018.

- Participation and membership in Startup Cities Alliance (SCALE) since April 2019, by all members of the CITIES network. SCALE is an initiative of global cities represented by public builders, who work together on strengthening local ecosystems through sharing their networks and learnings.

- Participation in the round table about smart cities organized by ACCIONA and 20 minutos (Madrid, Spain) about Smart Cities, June 2019.

- Participation in the round table about "Cities and technology" organized by Universidad Social de Vallecas (Madrid, Spain) and Universidad Politécnica de Madrid (Spain). Invited talk "Integrated and sustainable smart cities".

- Participation in the presential workshop at Universidad de la República, Uruguay, "International Workshop on Transportation Planning and Smart Cities", February 2019, with the academic participation of 15 researchers and administration authorities from Uruguay, Argentina, Chile, México, and Spain.

\subsection{Search and Detection of Potential Smart Cities Projects}

This activity was oriented to identify current initiatives that can interact synergistically with the main research, development, and training activities under development in the CITIES network. After an exhaustive search 67 relevant projects in more than 30 countries were detected.

The analysis of related projects and possibly joint initiatives among institutions of the network has increased the proposal and development of research projects, agreements with authorities and institutions, and other joint ventures. In turn, the registration on M.Sc. and Ph.D. programs has also increased in the participant institutions. 


\subsection{Research Stays and Mobility}

The CITIES network has promoted and funded research stays to develop joint works between research groups. A total number of 30 travel grants have been conceded, including travel for presential participation in the annual conference ICSC-CITIES. Most of the travels and research stays correspond to researchers from Latinamerican partners to develop activities in Spain. Participants from all countries of the network have developed mobility activities and research stays. In addition, 15 external participants from seven countries outside the network have developed mobility activities to participate in events organized by the network.

\subsection{Meetings with Authorities and Other Institutions}

A meeting was held with the Colombian Ministry of Education in 2018, and potential projects to be carried out with the Colombian Government have been identified.

The CITIES network was invited to participate in the Covenant of Mayors, an initiative of the European Union launched after the climate and energy package was adopted in 2008. The Covenant of Mayors co-operation movement involves local and regional authorities that voluntarily committed to increasing energy efficiency and the use of renewable energy sources on their territories.

\section{Forthcoming Activities}

The CITIES network is actively working in 2020 and has also specific activities planned for 2021. Regarding research, several on-going research and development projects are been developed and are planned to continue developing in the next year, including projects in the areas of energy efficiency, IoT and data analysis applied to public services, transportation design and planning, public services and governance, health, and others. A set of courses is also planned for 2020-2021, to expand the opportunities for formation of graduate and postgraduate students, and technicians.

Cooperation with authorities is also a crucial line of current and future work to guarantee the applicability of the proposed research and ideas by participating groups in the network. Contacts with stakeholders and companies in the sector are also been developed in order to foster new investment opportunities in targeted sectors. All developed networking activities also contributes to identify common problems and viable solutions to relevant issues in modern cities in Ibero-American countries.

The impact of the developed activities is shown in the high number of participants in courses, workshops, and conferences organized by CITIES. The number of joint research projects also demonstrates that the network is properly fulfilling the main objectives of promoting research and strengthen technical and professional training.

\section{Conclusions}

This article presented a description of the Ibero-American research network for integrated, sustainable, and efficient smart cities (CITIES), a research initiative to contribute with the development of smart cities in the Ibero-American region.

Both general and specific goals of the network were described. Institutions participating in the network were listed. The main activities developed within the network are described, including research, education, outreach, and dissemination. Finally, some key aspects of the current activities and main forthcoming activities were commented.

Author Contributions: Conceptualization, S.N. and L.H.-C.; writing-review and editing, S.N. and L.H.-C. All authors have read and agreed to the published version of the manuscript.

Funding: CITIES network is partly funded by CYTED, Ibero-American Program of Science and Technology for Development.

Acknowledgments: Authors acknowledge the contribution of all institutions and researches that are part of the CITIES network.

Conflicts of Interest: The authors declare no conflict of interest. 


\section{References}

1. Deakin, M.; Waer, H. From intelligent to smart cities. Intell. Build. Int. 2011, 3, 140-152. [CrossRef]

2. Townsend, A. Smart Cities: Big Data, Civic Hackers, and the Quest for a New Utopia; W. W. Norton \& Company: New York, NY, USA, 2013.

3. Nesmachnow, S.; Hernández Callejo, L. (Eds.) Revised selected papers. Communications in Computer and Information Science (CCIS). In Smart Cities, Proceedings of the First Ibero-American Congress of Smart Cities, ICSC-CITIES 2018, Soria, Spain, 26-27 September 2018; Springer: Berlin/Heidelberg, Germany, 2018; Volume 978.

4. Nesmachnow, S.; Hernández Callejo, L. (Eds.) Revised selected papers. Communications in Computer and Information Science (CCIS). In Smart Cities: Proceedings of the Second Ibero-American Congress of Smart Cities, ICSC-CITIES 2018, Soria, Spain, 7-9 October 2019; Springer: Berlin/Heidelberg, Germany, 2019; Volume 1152.

5. Nesmachnow, S.; Hernández Callejo, L. (Eds.) Special issue "mobility and IoT for the smart cities". Smart Cities 2020, 3, 2.

6. Hernández Callejo, L.; Alonso Gómez, V.; Nesmachnow, S.; Leite, V.; Prieto, J.; Ferreira, A. (Eds.) Special issue "CITIES: Energetic efficiency, sustainability; infrastructures, energy and the environment; mobility and IoT; governance and citizenship". Appl. Sci. 2020.

7. Proceedings of First Ibero-American Congress of Smart Cities, ICSC-CITIES 2018. Available online: https://easychair.org/cfp/icsc-cities-2018 (accessed on 23 July 2020).

8. Proceedings of Second Ibero-American Congress of Smart Cities, ICSC-CITIES 2019. Available online: http://www.icsc-cities2019.com/ (accessed on 23 July 2020).

9. Porteiro, R.; Hernández Callejo, L.; Nesmachnow, S. Electricity Demand Forecasting in Industrial and Residential Facilities Using Ensemble Machine Learning; Revista Facultad de Ingeniería Universidad de Antioquia: Antioquía, Colombia, 2020.

10. Padrón Nápoles, V.; Gachet Páez, D.; Esteban Penelas, J.; García Pérez, O.; García Santacruz, M.; Martín de Pablos, F. Smart bus stops as interconnected public spaces for increasing social inclusiveness and quality of life of elder users. Smart Cities 2020, 3, 430-443. [CrossRef]

11. Lafoz, M.; Navarro, G.; Torres, J.; Santiago, Á.; Nájera, J.; Santos-Herran, M.; Blanco, M. Power supply solution for ultrahigh speed hyperloop trains. Smart Cities 2020, 3, 642-656. [CrossRef]

12. Rossit, D.; Toutouh, J.; Nesmachnow, S. Exact and heuristic approaches for multi-objective garbage accumulation points location in real scenarios. Waste Manag. 2020, 105, 467-481. [CrossRef] [PubMed]

13. Lebrusán, I.; Toutouh, J. Using smart city tools to evaluate the effectiveness of a low emissions zone in Spain: Madrid central. Smart Cities 2020, 3, 456-478. [CrossRef]

14. Hipogrosso, S.; Nesmachnow, S. Analysis of sustainable public transportation and mobility recommendations for montevideo and Parque Rodó neighborhood. Smart Cities 2020, 3, 479-510. [CrossRef] 